\title{
A PANDEMIA DE COVID-19, DIREITOS HUMANOS E REFUGIO NO BRASIL
}




\section{POLÍTICA DE DIREITO AUTORAL}

Autores que publicam neste periódico concordam com os seguintes termos:

(a) Os autores mantêm os direitos autorais e concedem aos Cadernos de Pesquisa Direito Internacional sem Fronteiras o direito de primeira publicação, com o trabalho simultaneamente licenciado sob a Creative Commons Attribution License, permitindo o compartilhamento do trabalho com reconhecimento da autoria do trabalho e publicação inicial neste periódico.

(b) Os autores têm autorização para assumir contratos adicionais separadamente, para distribuição não exclusiva da versão do trabalho publicada nesta revista (ex.: publicar em repositório institucional), com reconhecimento de autoria e publicação inicial nesta revista.

(c) Os autores têm permissão e são estimulados a publicar e distribuir seu trabalho online (ex.: em repositórios institucionais ou na sua página pessoal) a qualquer ponto antes ou durante o processo editorial, já que isso pode gerar alterações produtivas, bem como aumentar o impacto e a citação do trabalho publicado.

(d) Os autores estão conscientes de que o periódico não se responsabiliza pela solicitação ou pelo pagamento de direitos autorais referentes às imagens incorporadas ao artigo. A obtenção de autorização para a publicação de imagens, de autoria do próprio autor do artigo ou de terceiros, é de responsabilidade do autor. Por esta razão, para todos os artigos que contenham imagens, o autor deve ter uma autorização do uso da imagem, sem qualquer ônus financeiro para os Cadernos de Pesquisa Direito Internacional sem Fronteiras.

\section{POLÍTICA DE ACESSO LIVRE}

Este periódico oferece acesso livre imediato ao seu conteúdo, seguindo o princípio de que disponibilizar gratuitamente o conhecimento científico ao público proporciona sua democratização.

Dados Internacionais de Catalogação na Publicação (CIP)

CA111 Cadernos Eletrônicos Direito Internacional sem Fronteiras

[recurso online] / Portal Direito Internacional sem

Fronteiras - Vol. 2, n. 1 (2020) - Juiz de Fora: Portal Direito

Internacional sem Fronteiras, 2020.

\section{Semestral}

Modo de acesso: Internet.

ISSN: 2675-2514

1. Direito Internacional. 2. Relações Internacionais. 3. Direito.

I. Portal Direito Internacional sem Fronteiras. II. Título. 
CORPO EDITORIAL

Cadernos de Pesquisa Direito Internacional sem Fronteiras, vol. 2, n. 1 (2020)

Revisão

Fernanda Barroso e Silva

Mestranda em Letras, pela Faculdade de Letas da Universidade Federal de Juiz de Fora (Brasil)

\section{Autores}

Estela Cristina Vieira de Siqueira

Doutoranda em Direito Internacional Público, pela Faculdade de Direito da Universidade de São Paulo (Brasil)

Matheus Presotto e Silva

Especialista em Direito Internacional, pelo Centro de Estudos em Direito e Negócios (Brasil)

Raian Mateus Castelo Branco Costa

Bacharelando em Direito, pela Faculdade de Direito, da Universidade Estadual do Piauí (Brasil)

Vinicius Villani Abrantes

Bacharelando em Direito, pela Faculdade de Direito, do Instituto Metodista Granbery (Brasil)

Bacharelando em Letras, pela Faculdade de Letras, da Universidade Federal de Juiz de Fora (Brasil)

Wanda Helena Mendes Muniz Falcão

Doutoranda em Direito Internacional Público, pela Faculdade de Direito da Universidade Federal de Santa Catarina (Brasil)

SIQUEIRA, Estela Cristina Vieira de; SILVA, Matheus Presotto e; COSTA, Raian Mateus Castelo Branco; ABRANTES, Vinicius Villani; MUNIZ FALCÃO, Wanda Helena Mendes. A Pandemia de Covid-19, Direitos Humanos e Refúgio no Brasil. Cadernos de Pesquisa Direito Internacional sem Fronteiras, Juiz de Fora, v. 2, n. 1, p. 1-34, jan/jun 2020.

$\mathrm{Ou}$

SIQUEIRA, Estela Cristina Vieira de et al. A Pandemia de Covid-19, Direitos Humanos e Refúgio no Brasil. Cadernos de Pesquisa Direito Internacional sem Fronteiras, Juiz de Fora, v. 2, n. 1, p. 1-34, jan/jun 2020. 


\section{A PANDEMIA DE COVID-19, DIREITOS HUMANOS E REFÚGIO NO BRASIL}

SUMÁRIO: 1 INTRODUÇÃO: ENTRE DESAFIOS E INCERTEZAS, DESAPONTA A COVID-19; 2 DIREITO INTERNACIONAL EM TRANSFORMAÇÃO E O SUJEITO REFUGIADO; 2.1 Direito Internacional dos Direitos Humanos, dos Refugiados e Humanitário; 2.2 Quem são Os Refugiados; 2.3 OMS, o direito à saúde e a saúde dos refugiados; 3 PANORAMA DOS REFUGIADOS NO BRASIL; 3.1 O Brasil como País de Acolhimento; 3.2 A Constituição Federal de 1988; 4 SIDH, OS REFUGIADOS E A COVID-19; 5 CONSIDERAÇÕES FINAIS; APÊNDICE 1 - DECLARAÇÃO 01/2020 DE 09 DE ABRIL DE 2020 DA CORTE INTERAMERICADA DE DIREITOS HUMANOS; APÊNDICE 2 - RESOLUÇÃO No 1/2020 - PANDEMIA E DIREITOS HUMANOS NAS AMÉRICAS (OEA); APÊNDICE 3 - RESOLUCIÓN DE LA PRESIDENTA DE LA CORTE INTERAMERICANA DE DERECHOS HUMANOS DE 26 DE MAYO DE 2020

\section{INTRODUÇÃO: ENTRE DESAFIOS E INCERTEZAS, DESPONTA A COVID-19}

Em dezembro de 2019, na cidade de Wuhan, na China, foram identificados os primeiros casos de uma nova doença, a COVID-19, provocada por um dos tipos de coronavírus (Sars-Cov2). Tal enfermidade é responsável por causar graves transtornos respiratórios nos contaminados. Em março de 2020, a Organização Mundial da Saúde, doravante OMS, reconhece oficialmente a pandemia da nova doença.

Nesse contexto, a Organização supracitada estimulou os Estados a criarem ações imediatas para o combate a nova doença e principalmente meios de mitigar a sua propagação. Dessa maneira, para atenuar e, por conseguinte, impedir o aumento acelerado do contágio, diversos países adotaram, por meio de leis e decretos, políticas como o "distanciamento social" e "isolamento social". Além disso, em determinadas regiões, como foi o caso da Itália, foram empregadas medidas ainda mais severas, de bloqueio total, o chamado lockdown.

A pandemia atingiu gravemente diversos setores estatais, especialmente em países mais pobres do globo terrestre, - de acordo com Boaventura Sousa Santos (2020), a crise permanente, instaurada em 1980, com a pandemia apenas evidenciou as "brechas sociais" -. $A$ pandemia é uma alegoria. São centenas de pessoas sem acesso à água potável, a saúde básica, 
alimentação equilibrada e moradia digna. Nessa ambiência, ainda é importante referenciar o Guía Práctica de Respuestas Inclusivas y con Enfoque de Derechos ante el COVID-19 en las Américas, elaborado pela Organização dos Estados Americanos, que aponta as inúmeras outras situações de vulnerabilidades que carecem de ações diretas dos governos.

Dentro desses grupos de vulnerabilidade mencionados, encontram-se aqueles que estão em condição de migrações internacionais forçadas, quais sejam os refugiados, apátridas e migrantes em decorrência de mobilidade forçada. Neste ponto, convém sublinhar a desproporcionalidade do efeito da pandemia para essa população. Definindo aqui um enfoque maior para os refugiados, será buscado demonstrar a afetação acentuada da crise do sistema de saúde para aqueles que tem o Brasil como Estado acolhedor.

Portanto, o presente estudo, desenvolvido pelos pesquisadores do Direito Internacional sem Fronteiras, tem como objetivo, realizar um panorama sobre o contexto, a partir da perspectiva do Sistema Interamericano de Direitos Humanos, e dos mecanismos jurídicos internos para a proteção do refugiados, evidenciando o Direito à Saúde, garantido em nacionalmente pela Lei 8.080/90 (Lei Orgânica da Saúde) e pela Constituição Federal de 1988 - sem distinção para todos, seja migrante ou cidadão brasileiro, configurando desse modo, como obrigação primeva do Estado fornecer uma saúde de qualidade que não leve em conta estigmas ou preconceitos.

\section{DIREITO INTERNACIONAL EM TRANSFORMAÇÃO E O SUJEITO REFUGIADO}

O Direito Internacional ${ }^{1}$ é atribuído como a vertente ligada ao sistema internacional, aplicado em diversas relações (PEREIRA, 2009). Seria possível subdividir em dois grandes grupos: o Direito Internacional Público e o Direito Internacional Privado - o primeiro ramo, em uma visão mais tradicional, sempre buscou pela manutenção da paz perante as diversas assimetrias dos atores internacionais. Entretanto, com os movimentos de globalização,

\footnotetext{
1 Também chamado de "direito das gentes" e "direito externo". A nomenclatura "direito internacional", inclusive adotada nesta pesquisa, foi idealizada por Bentham em 1780, com o sentido de oposição à ideia de national law.
} 
principalmente os perversos (SANTOS, 2011), gerando diversas transformações nos cenários sociais e políticas, exigiu mudanças inovadoras nos postulados internacionais.

O direito internacional público regula as relações internacionais, ou seja, as relações entre os Estados, - os principais atores da vida mundial, - as nações em luta pela independência política e as organizações internacionais, cada vez mais importantes e numerosas (MONSSERRAT FILHO, 1986, pp. 18-19).

É evidente que com a criação da Declaração Universal de Direitos Humanos, em 1948, inicia-se uma nova estrutura para o Direito Internacional (dos Direitos Humanos) - o Estado deixa de ser visto como como um fim em si mesmo, e passa a ser apontado como um dos instrumentos importantes para a proteção e preservação dos direitos humanos (RODRIGUES; BIAZATTI, 2016), pensamento que é veemente apontado pela doutrina e jurisprudência internacional.

Nessa ambiência, se estabelece que um aspecto fundamental do sistema normativo internacional seria a proteção dos direitos fundamentais da pessoa humana - cabe aqui apontar, então, uma disposição dos Estado nacionais, na matéria de direitos humanos, a normas e diretrizes provenientes das Cortes Internacionais.

\subsection{Direito Internacional dos Direitos Humanos, dos Refugiados e Humanitário}

É sabido que os direitos humanos ${ }^{2}$ integram-se dos direitos individuais fundamentais, como vida, liberdade, igualdade, segurança, dentre outros; dos direitos sociais, como trabalho, saúde, educação, dentre outros; dos direitos econômicos, como pleno emprego, meio ambiente, dentre outros; e dos direitos políticos, como formas de realização da soberania popular. Dessa

\footnotetext{
2 A nomenclatura "Direitos Humanos" abarca questionamentos extremamente importantes e consequentemente desafiadores para a disciplina. É possível observar que as seguintes terminologias aparecem demarcando a mesma ideia: "direitos naturais, direitos humanos, direitos do homem, direitos individuais, direitos públicos subjetivos, liberdades fundamentais, liberdades públicas e direitos fundamentais do homem", inúmeras outras. De acordo com Tavares (2002), aponta que muitas dessas nomenclaturas apresentam semânticas coincidentes e por isso são usadas, mas cabe ressaltar que carece de uma abordagem mais técnica e crítica sobre essa designação. Portanto, cabe aqui salientar o posicionamento de José Castan Tobenas (1998), o autor define "direitos humanos" como os direitos fundamentais da pessoa humana, isto em razão de sua própria natureza. Nessa perspectiva, os direitos devem ser assegurados e respeitados por todos os poderes e autoridades. É válido dizer que a própria doutrina reconhece a dificuldade em se definir de maneira direta e única "direitos humanos", quaisquer tentativas de se determinar uma denominação fechada para a nomenclatura será insatisfatória.
} 
maneira, sabe-se que o conjunto de direitos individuais exposto anteriormente se completam de tal maneira que sem a existência de todos eles, torna-se irreal a totalidade dos direitos humanos.

O pós-segunda guerra pode ser considerado um grande palco para brusca mudança do direito internacional, como mencionado anteriormente, serviu para emergir a tensão e a necessidade entre dialéticas de proteção internacional dos direitos humanos. Nessa perspectiva, essa necessidade de efetividade aos direitos humanos fez nascer, no cenário internacional, um novo campo vinculado ao direito internacional público, que se denominou de "direito internacional dos direitos humanos".

Dessa maneira, o direito internacional dos direitos humanos tem por objetivo de estabelecer e assegurar condições adequadas para salvaguardar toda pessoa humana de quaisquer violações de seus respectivos direitos. Então, torna-se claro que é um direito de proteção, operando em favor dos mais vulneráveis, nas relações assimétricas (PIOVESAN, 2011). O Direito Humanitário é conhecido como o direito que rege os conflitos armados, eria como objetivo é construir parâmetros para o direito de guerra, em outras palavras, possui uma perspectiva de auxílio humanitário (PEREIRA, 2009).

O Direito Internacional dos Refugiados possui a finalidade de proteger os migrantes de crise por motivos de raça, nacionalidade, opinião política, religião ou pertencimento a determinado grupo social. De acordo com Jubilut (2007), o direito internacional dos refugiados é um dos instrumentos que gera aos migrantes deslocados forçados, direitos básicos e correlacionados aos seres humanos. Se torna evidente, então, que apesar das três esferas comunicarem diretrizes clássicas e fundamentais do direito internacional público, são troncos que possuem suas características e autonomia.

É importante mencionar que as pesquisas que analisam os processos de acolhimento e integração dos refugiados trazem consigo a necessidade de se aportarem ao direito internacional público e direito internacional dos direitos humanos - é uma das fontes mais relevantes para a integralidade da proteção dos direitos dos refugiados. 


\subsection{Quem são os refugiados?}

Brought up in the conviction that life is the highest good and death the greatest dismay, we became witnesses and victims of worse terrors than death-without having been able to discover a higher ideal than life. (ARENDT, 1943)

O cerne informativo do reconhecimento do status de refugiado dentro do sistema normativo da Organização das Nações Unidas, uma consequência da garantia ao direito que todo ser humano tem de buscar asilo, conforme a Declaração Universal dos Direitos Humanos (1948), consiste no fundado temor de perseguição, que coloque em risco a vida ou a integridade física do indivíduo, em razão de raça, religião, opinião política. Sendo assim, desde a Convenção de 1951 sobre o Estatuto dos Refugiados (ONU, 1951), a definição jurídica do instituto, bem como suas possibilidades de concessão, é bastante limitada, não incluindo indivíduos que deixem seu lugar de origem em razão de catástrofes ambientais ou econômicas.

Contudo, no momento histórico de criação do texto convencional, em 1951, a definição era ainda mais restrita, ratione temporis e ratione personae, destinando a proteção apenas aos refugiados europeus da Segunda Guerra Mundial (ONU, 1951), na esperança de que, após a elevada proporção do conflito de 1939-1945, a humanidade não mais insistiria em conflitos armados - expectativa que brevemente seria frustrada, com a Guerra da Coreia (finda em 1953) e tantos outros conflitos regionais, durante a Guerra Fria.

Assim, em 1967, um Protocolo ao texto original, o Protocolo Relativo ao Estatuto dos Refugiados (ONU, 1967), removeu as limitações temporais e geográficas da definição de refúgio, tornando o conceito mais abrangente, de forma a incluir também refugiados oriundos de outros conflitos e outras partes do globo. Ainda assim, a definição era restritiva, e não incluía, por exemplo, vítimas de graves e massivas violações de Direitos Humanos, o que só ocorreria em dois documentos regionais, no contexto Latino-Americano (que sofria com inúmeros governos autoritários) e Africano, na Convenção da Organização da Unidade Africana (OUA), atual UA, que rege os aspectos específicos dos aspectos dos Refugiados em África, de 1969, e na Declaração de Cartagena, em 1984. 
No entanto, o refugiado, assim declarado por seu status legal, é mais do que uma expressão normativa, utilizada amplamente em documentos internacionais. Estamos a falar de uma pessoa, de um ser humano, com suas particularidades, individualidade e autonomia, no século das grandes migrações. Não se trata, contudo, de romantizar a migração, sobretudo a migração forçada, da qual o refúgio é gênero, apenas de abordá-la sob um outro viés, que não o securitário, no centro da tensão entre política de migração e política de controle (MEZZADRA, 2012).

Sendo humano, portanto, ele é destinatário de direitos humanos, tais como o direito à saúde - recordando-nos que os direitos humanos são indivisíveis e que o direito à vida e à vida digna não são possíveis sem a garantia do direito à saúde, conforme disposto na DUDH e no artigo 12 do Pacto Internacional de Direitos Econômicos e Sociais (1966) advindo dela, sendo os Estados-partes do texto vinculados ao reconhecimento do direito de "desfrutar do mais elevado nível de saúde física e mental”.

\subsection{OMS, o direito à saúde e a saúde dos refugiados}

E sobre esse direito de ter sua saúde mental e física garantidos em qualquer contexto, certamente, quando falamos em mobilidade, um dos direitos mais difíceis de se proteger é o de acesso à saúde, sobretudo quando consideramos todos os desafios enfrentados pelos refugiados, nos processos de deslocamento forçado. 0 alto custo de tratamentos e acesso a medicação se torna um problema adicional para quem, involuntariamente, tem de deixar o lar de origem para trás.

Segundo o plano de resposta internacional do Alto Comissariado das Nações Unidas para Refugiados, o ACNUR, dos 196 países afetados pelo COVID-19 até março, 79 eram países que realizam acolhimento de refugiados (UNHCR, 2020), o que reforça a necessidade de se pensar soluções conjuntas para o combate à doença, como a manutenção de serviços básicos e essenciais de saúde (SAN LAU, et al, 2020), nesse ano de 2020, conforme será abordado mais à frente quanto ao contexto regional do Sistema Interamericano, mas sem perder de vista o aprendizado adquirido em outras emergências de saúde internacional anteriores, como o Ebola e o HIV.

Nesse sentido, a Organização Mundial da Saúde, a agência especializada das Nações Unidas para Saúde, evoluiu historicamente, enquanto órgão, desde 1948, embora a preocupação internacional com a saúde coletiva exista desde o século XIX (HUBER, 2006) - muito antes da expressão Emergência de Saúde Pública de Importância Internacional (PHEIC) ser parte do vocabulário cotidiano dos 
noticiários. Desde 1851, especialistas em saúde têm se reunido para criar protocolos conjuntos de combate a doenças como cólera e surtos eventuais de peste bubônica.

Porém, seria apenas no contexto da Organização das Nações Unidas que a humanidade conheceria o arranjo institucional da OMS, cuja Constituição, que entrou em vigor em 1948 (WORLD HEALTH ORGANIZATION), afirmaria a importância do apoio técnico e institucional aos Estados, fornecido por uma agência voltada exclusivamente à proteção de um dos direitos mais importantes à garantia do direito à vida, independentemente de nacionalidade, religião ou origem étnica: a saúde. $\mathrm{E}$ é vital que esse direito seja estendido a refugiados, igualmente.

Sobretudo quando falamos de refugiados que já se encontrem em campos de refugiados, é especialmente mais complexo manter as normas de distanciamento social que uma Emergência de Saúde Pública de Importância Internacional ensejam, apesar de, de fato, já se encontrarem isolados embora não entre si, devido ao limitado espaço em que se encontram, das dificuldades de acesso a água e insumos de higiene, como sabão, e outras questões relacionadas ao saneamento básico (KLUGE, et al, 2020). Não há como se falar em auto isolamento em um campo de refugiados (RAJU, et al, 2020).

Uma outra grave consequência se dá em razão do fechamento de fronteiras aos migrantes, de toda sorte, o que não é um problema grave para aqueles que migram voluntariamente. Mas quando falamos de refugiados, isso pode significar o risco de devolução ao lugar de origem, violando um dos mais importantes princípios de proteção aos deslocados forçados, o Princípio do Non-Refoulement (KLUGE, et al, 2020), o direito de não ser devolvido ao lugar de origem, caso isso represente um risco à vida do refugiado. Um risco adicional, comum também aos não-refugiados, é o de desinformação, tendo em vista que informações falsas se espalham rapidamente, agora, no contexto da pandemia (RAJU, et al, 2020).

Portanto, a inclusão de refugiados no sistema de saúde doméstico dos Estados de acolhimento, sem que isso represente um custo a eles, em razão de sua condição humanitária, é uma resposta necessária dos sistemas de saúde, uma discussão que não é recente (CAULFORD; VALI, 2006), mas que devido à gravidade da situação, faz-se emergencial, livrando-os também do estigma de serem vetores do COVID-19 (KLUGE, et al, 2020), enquanto estrangeiros, o que fora estimulado pelos episódios xenofóbicos que se seguiram ao início da emergência internacional, sobretudo quanto a indivíduos de origem asiática.

Percebemos, assim, a necessidade de se analisar como os Estados têm respondido à pandemia, não apenas em um contexto global, conjuntamente, mas também a nível doméstico e local, onde as 
reais medidas, eficazes ou não, serão operadas no combate à emergência sanitária, de forma a que procederemos, a seguir, a compreender como o Brasil figura como país de destino de migração, sobretudo quanto ao deslocamento forçado, e como o Sistema Interamericano tem reagido ao atual momento.

\section{PANORAMA DOS REFUGIADOS NO BRASIL}

\subsection{O Brasil como país de destino}

A imagem internacional de que o Brasil é um país acolhedor esbarra na falta de estrutura adequada que continuamente se torna entrave para a real efetivação dos dispositivos legais do país no tocante a concessão de refúgio. Ainda assim, a alegórica ideia de que esta é uma terra que protege Direitos Humanos encontra amparo nas tradições diplomáticas abertas e democráticas que o Brasil manteve e mantém com o resto do mundo. Para além das boas relações políticas, a diversidade de sua população e a alegria do seu povo reafirmam o maior país da América do Sul como uma referência aos deslocados forçados ao buscarem um local de proteção no qual poderão reconstruir com segurança as suas vidas e as de sua família.

De fato, não apenas pelos motivos supracitados, mas também devido a sua legislação, o Brasil consagrou-se como uma nação de boas práticas possuindo uma política nacional focada em direitos. Em grande medida, essa política deve-se ao fato de que o Brasil é signatário dos principais Tratados Internacionais de Direitos Humanos e é também, parte da Convenção das Nações Unidas de 1951, ratificada no ordenamento nacional a partir de julho de 1997 com o chamado Estatuto dos Refugiados (Lei $n^{\circ}$ 9.474/97) que garante a responsabilização internacional do nosso país frente ao tema. Ainda nesse dispositivo legal, nos deparamos com um grande avanço, ao ser reconhecido o conceito expandido do termo refugiado, que passa a abarcar então o indivíduo que "devido a grave e generalizada violação de direitos humanos, é obrigado a deixar seu país de nacionalidade para buscar refúgio em outro país" (Art $1^{\circ}$, inciso III, Lei n 9.474, BRASIL, 1997). 
No âmbito mundial, os fluxos migratórios se intensificaram de forma alarmante nos últimos 10 anos, sendo possível traçar três populações principais que passaram a se deslocar em razão de graves violações de direitos humanos e buscaram o Brasil como país de destino: a população síria, haitiana e venezuelana. As populações sírias e haitianas encontram-se nessa situação desde meados de 2010 - 2011, com ápice em 2014 e 2016, quando de acordo com o Comitê Nacional para os Refugiados, doravante CONARE, houve um aumento de $12 \%$ do número de refugiados sírios no país. No entanto, a população síria reduziu vertiginosamente sua entrada no país desde então, inclusive foi a nacionalidade que mais obteve sucesso em número de deferimentos de concessão de refúgio no ano de 2016 (com total de 326 versus apenas 14 de Venezuelanos, segundo dados do relatório Refúgio em Números, de 2018). O Haiti, por sua vez, embora com um número consideravelmente inferior aos da Venezuela, que vem mantendose como líder no ranking de solicitações no Brasil desde o ano de 2016, ainda apresenta grande demanda, como demonstra a tabela a seguir.

\section{GRÁFICO 1 - SOLICITAÇÃO DE REFÚGIO POR PAÍS DE ORIGEM EM 2016}

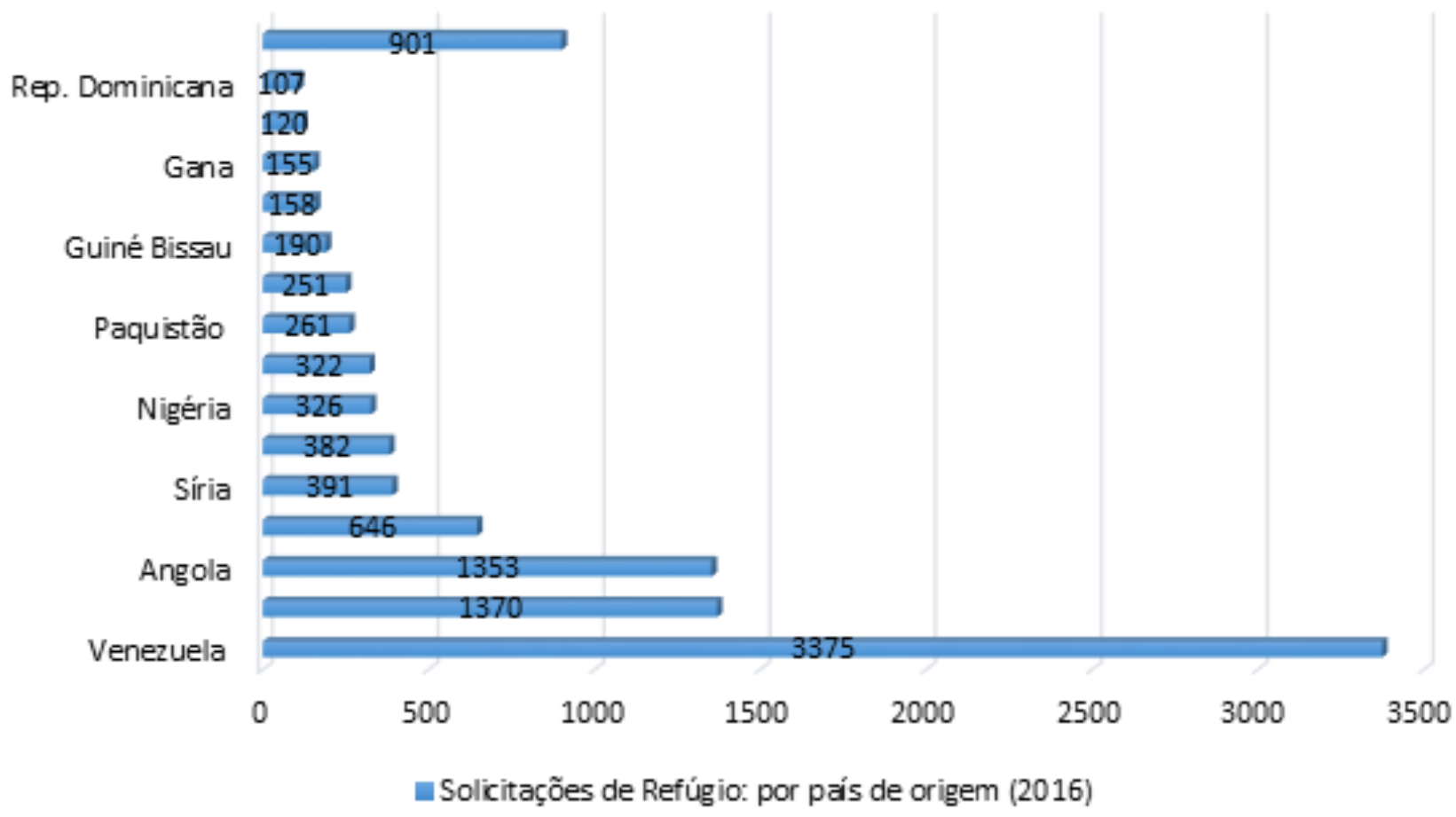


No gráfico acima, criado a partir de dados divulgados pelo relatório "Refúgio em números" da Secretaria Nacional de Justiça, que ilustra o período de 2010-2016 e confrontando esse histórico com a versão mais recente do documento “Refúgio em números”, lançada em 2019, é possível estabelecer o padrão de crescimento que reforça a posição da Venezuela como líder atual em solicitações de refúgio.

Apenas em 2018, o Brasil recebeu 80.057 solicitações de refúgio de estrangeiros. Desse número, 61.681 foram feitas por venezuelanos. Os dados são de balanço divulgado pelo Comitê Nacional para os Refugiados (CONARE) e pela Agência da ONU para Refugiados (ACNUR). A pesquisa mostrou ainda que o Brasil acumulava naquele ano mais de 160 mil pedidos de refúgio em análise, feitos em 2018 e em anos anteriores. Desses requerimentos, 52\% são de venezuelanos; $10 \%$, de haitianos; $5 \%$, de senegaleses; e $4 \%$, de cubanos (NAÇÕES UNIDAS BRASIL, 2019). Como ilustra o gráfico abaixo.

\section{GRÁFICO 2 - SOLICITAÇÕES DE REFÚGIO POR PAÍS DE ORIGEM EM 2018}

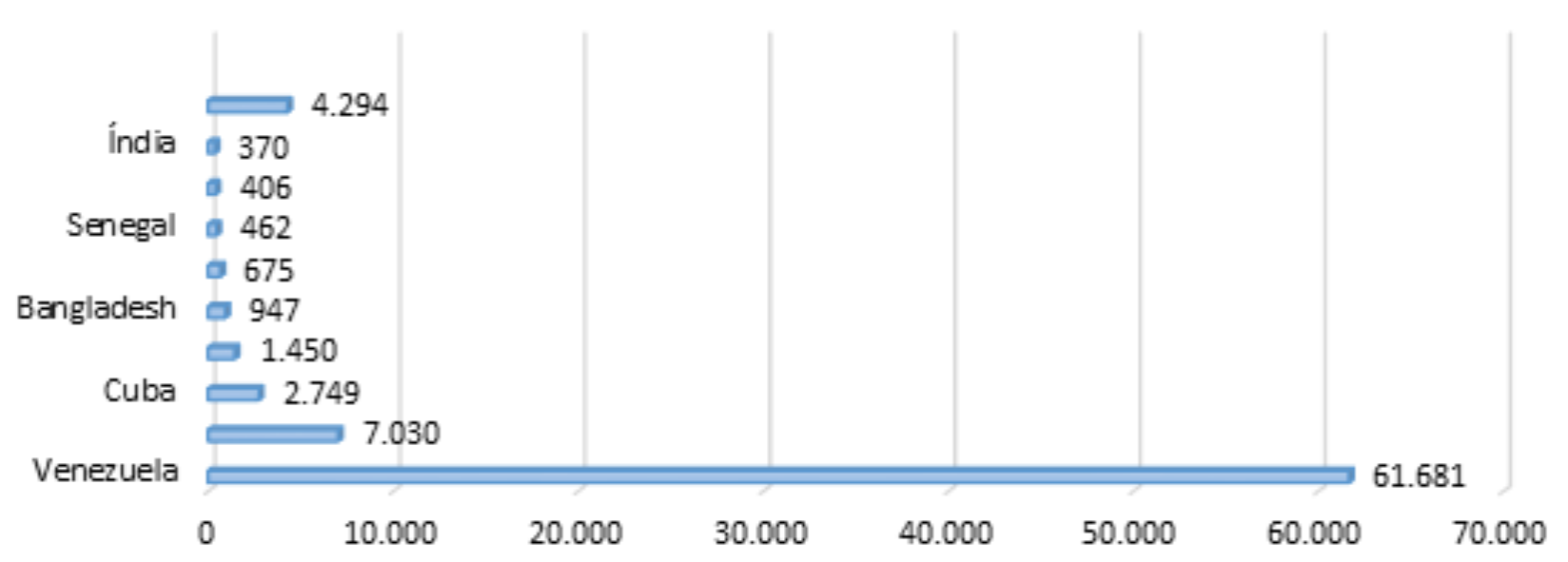

$\square$ Solicitações de reconhecimento da condição de refugiado por país de origem em 2018

FONTE: Polícia Federal em 02 de janeiro de 2019, adaptado do documento "Refúgio em números" do CONARE e do ACNUR de 2019

Em uma decisão com impacto importante no cenário nacional, o CONARE reconheceu, em junho de 2019, a situação de "grave e generalizada violação de direitos humanos" na Venezuela, nos termos do inciso III do artigo $1^{\circ}$ da Lei $n^{\circ} 9.474$, de 1997 . A decisão possibilita, a partir de agora, a adoção de procedimento simplificado no processo de determinação da 
condição de refugiado para nacionais venezuelanos, mas não dispensa os interessados da entrevista de elegibilidade (BRASIL, 2019).

Portanto, é a partir destas informações que o Brasil deve se orientar e traçar diretrizes de ação. Além da nacionalidade, vale ressaltar a importância de ações interseccionais que visem políticas voltadas às especificidades de gênero e faixa-etária dessas pessoas em mobilidade. Acerca disto, mulheres e crianças são parte da população que convive diuturnamente com situações de vulnerabilidade social, pois seus quadros são produto de construções de marginalização e estigmatimações estruturais.

Em diversas sociedades, especialmente àquelas que perpassaram por experiências colonialistas, expressões do patriarcalismo e do machismo se colocam como conformadoras e ensejam pontos de tensão nas relações sociais, além disso, o adultocentrismo. As duas primeiras marcas se voltam para o público-alvo das mulheres (e por decorrência das demais performances de gênero) e a última para as crianças, sem dúvidas, estes são dois grupos que por força de composições histórico-cultural da sociedade da qual pertence, são colocados às margens.

Dada tal característica, depreende-se que, se o indivíduo que faz parte de estratos propensos a deslocar-se forçadamente é o que está em posição periférica, mulheres e crianças têm locus ainda mais lateral. Isso se revela pelos processos de subalternização (SPIVAK, 2014) que são inerentes e, infelizmente, impulsionam violações de direitos potencialmente aliadas aos fatores que conduzem à saída compulsória do seu local de origem. Neste caminho, a terra árida para a refugiada e para os pequenos se demonstra de forma mais dolorosa, pois, uma vez produtos de hierarquias, são vítimas nos lugares de acolhida e no intertexto até o ponto de chegada.

No mundo, mais de um terço de refugiados é de mulheres e crianças, a maior parte do número é de menores de 18 anos. Tais dados demonstram as condições de inferioridade vinculadas e que tanto a comunidade internacional - numa leitura de cooperação entre Estados e organizações internacionais - quando os países de acolhida necessitam criar planos de ações 
e estratégias suficientes para atender as demandas específicas que contornam a situações destas pessoas.

O Brasil se aloca na porção de países que detém no seu desenho político fraturas quanto ao trato de políticas públicas direcionadas para estas populações, pois é sociedade constituída pelo machismo, patriarcalismo, adultocentrismo e pelo menorismo - este último é ponto em comum com outros países da América Latina, pois há repressão e estigmatização às figuras dos "menores”. Dentro deste espaço, a legislação civil nacional indicava claramente divisões hierárquicas entre homens e mulheres, sendo a normatização e normalização de discriminações com recorte de gênero; para as crianças e adolescentes, os Códigos de Menores de 1927 e 1979. Isto é, se para os seus nacionais - aqui afirmando a posição duradora nacionalista, discriminatória e securitária para os "estrangeiros" - o Direito assim se expressava, para aquelas para mulheres e crianças não brasileiras a posição era de silêncio e violação.

Com a re-democratização em 1985 e posteriormente com a Constituição Federal de 1988 - tema este melhor discutido abaixo -, questões pontuais quanto às garantias fundamentais são colocadas na pauta central e de busca por linhas de emancipação, igualdade e reconhecimento de direitos, mulheres estariam equiparadas a homens no exercício de sua cidadania, bem como crianças e adolescentes seriam sujeitos de direitos. Esta inovação não distinguiu brasileiros de outros nacionais, a nova Constituição seria janela para um Brasil que gostaria de ser atualizado para a leitura de um mundo pautado nas diretrizes que o Direito Internacional dos Direitos Humanos já orientaria desde 1945 com a criação da ONU e em 19848 com a Declaração Universal de Direitos Humanos.

Porém, tendo ainda a vigência do Estatuto do Estrangeiro, estas divisões eram divergentes da matéria constitucional e dos instrumentos internacionais, em 2017 é promulgada a Lei de Migrações e nisto se dá a visibilidade a estes dois grupos, porém há estrada a ser percorrida pelo o Estado brasileiro e pela sociedade em geral. Mulheres e crianças não brasileiras e, especificamente, na condição de refugiadas necessitam de maior investimento em 
políticas públicas não apenas de acolhimento, inserção, mas também de criação de possibilidade de vencimento das fraturas que acompanham historicamente estas pessoas.

\subsection{A Constituição Federal de 1988}

O direito constitucional brasileiro vem incorporando determinações que norteiam diversas competências que tangenciam a esfera internacional, da mesma maneira que parâmetros para a manutenção e promoção da paz. Mazzuoli (2007) aponta que a promulgação da Constituição Federal de 1988 traz as garantias aos direitos fundamentais dos cidadãos, de maneira a positivar os direitos humanos. Ainda a promulgação da nova Carta mostra a abertura do sistema jurídico brasileiro para a chamada nova ordem de proteção e garantias às pessoas humanas.

A Constituição Federal do Brasil apresenta diretrizes para as ações do Estado nacional dentro do ordenamento interno e no cenário internacional. No que tange à jurisdição interna, exemplifica-se com o artigo $3^{\circ}$, inciso IV, que prevê a promoção ao bem coletivo sem qualquer tipo de atos preconceituosos - incluindo-se aqui a origem dos indivíduos. À luz do artigo $4^{\circ}$ da Lei Máxima é possível perceber os princípios que regem as relações internacionais do Brasil - nenhuma dúvida se tem de que da prevalência e promoção dos direitos humanos e da concessão de asilo, fica evidente a proteção dos migrantes como sujeitos de direitos dentro do âmbito interno.

Art. $5^{\circ}$ Todos são iguais perante a lei, sem distinção de qualquer natureza, garantindo-se aos brasileiros e aos estrangeiros residentes no País a inviolabilidade do direito à vida, à liberdade, à igualdade, à segurança e à propriedade, nos termos seguintes (BRASIL, 1988).

O caput do artigo supracitado apresenta o tratamento igualitário - democrático - entre todos os nacionais e os indivíduos estrangeiros que estão em território nacional. A Constituição Federal propõe pontos básicos para a jurisdição brasileira na elaboração de políticas afirmativas para a acolhimento dos refugiados, entretanto, é importante salientar o posicionamento da Jubilut (2007), os direitos apresentados na Carta magna não se concretizam 
por si só, dessa maneira, a existência de uma legislação que promove essas garantias é apenas um dos primeiros passos para a efetivação dessa proteção.

\section{SIDH, OS REFUGIADOS E A COVID-19}

No momento em que este trabalho é escrito, a humanidade enfrenta um dos maiores desafios da contemporaneidade em matéria de saúde pública, decorrente da pandemia causada pelo novo coronavírus (COVID-19). Não obstante, uma série de consequências políticas, jurídicas e econômicas também são suportadas por nações e seus cidadãos em todos os continentes.

A escalada da doença, na medida em que nos iguala ao não escolher quais os países afligidos, pessoas infectadas e vidas ceifadas, nos diferencia quanto à resposta a ela dada, isto é, quanto às medidas de enfrentamento adotadas neste momento. Da mesma forma, os impactos sobre determinadas populações são muito distintos, haja vista que aqueles grupos historicamente hipossuficientes e em vulnerabilidade serão os mais castigados pela doença e pelas medidas de enfrentamento à crise de saúde pública.

Diante disso, os olhos atentos do jurista se voltam para o arcabouço de direitos fundamentais (aqui, sinônimos de Direitos Humanos) e seus instrumentos de implementação, a fim de minimizar os impactos deletérios sobre todos nós, sujeitos de tais direitos.

A abordagem constitucional da matéria foi apresentada em tópico anterior, motivo pelo qual este tópico tratará das normas e ferramentas supranacionais, oriundas do Sistema Interamericano de Direitos Humanos (SIDH) aplicável ao Brasil, com o intuito de ampliar o escopo dos direitos humanos e instrumentalizar o arcabouço jurídico nacional para a escorreita implementação de tais direitos e suas garantias.

O Sistema Interamericano de Direitos Humanos (SIDH) inaugurado pela Convenção Americana de Direitos Humanos (Pacto de San José da Costa Rica, 1969), composto pela Comissão Interamericana de Direitos Humanos (CIDH) e pela Corte Interamericana de Direitos Humanos (Corte IDH) surgiu no contexto de evolução do direito internacional do pós-guerra, 
sendo o segundo sistema regional de proteção dos direitos humanos inaugurado pela humanidade, antecedido no tempo pelo Sistema Europeu (Convenção Europeia de Direitos Humanos, 1950) e sucedido pelo Sistema Africano (Carta Africana de Direitos Humanos e dos Povos, 1981).

Os sistemas regionais de direitos humanos contribuíram para a difusão regional da ideia de que o Estado não é o único sujeito de direito internacional, na medida em que passaram a aceitar reivindicações de indivíduos em nível internacional. Tal movimento deu início à revisão dos conceitos clássicos de (i) sujeito de direito internacional ${ }^{3}$ e (ii) soberania, admitindo-se um certo grau de intervenção internacional no âmbito interno dos países, a fim de amparar e garantir o respeito aos direitos humanos.

O Brasil, como Estado membro da Organização dos Estados Americanos, participou da criação e do estabelecimento do SIDH. Ratificou a Convenção Americana de Direitos Humanos e aceitou a jurisdição obrigatória da Corte Interamericana de Direitos Humanos ${ }^{4}$ (Corte IDH), bem como as competências da Comissão Interamericana de Direitos Humanos (CIDH) para a

\footnotetext{
${ }^{3}$ Após o paradigma pós-westfaliano, sujeitos de direito internacional seriam somente os Estados; passados centenas de anos, em meados do séculos XIX-XX, passou-se a admitir a personalidade jurídica internacional das Organizações Internacionais e, somente após a II Guerra Mundial o indivíduo passou a ser admitido, ainda que com algumas restrições, como sujeito de direito no âmbito internacional com o advento dos sistemas regionais de direitos humanos consolidando-se, no século XXI, como sujeito de direitos e obrigações a partir do Estatuto de Roma e da inauguração do Tribunal Penal Internacional.
}

${ }^{4}$ DECRETO N 4.463, DE 8 DE NOVEMBRO DE 2002. Promulga a Declaração de Reconhecimento da Competência Obrigatória da Corte Interamericana de Direitos Humanos, sob reserva de reciprocidade, em consonância com o art. 62 da Convenção Americana sobre Direitos Humanos (Pacto de São José), de 22 de novembro de 1969 . 0 PRESIDENTE DA REPÚBLICA, no uso da atribuição que the confere o art. 84, inciso IV, da Constituição, e Considerando que pelo Decreto no 678, de 6 de novembro de 1992, foi promulgada a Convenção Americana sobre Direitos Humanos (Pacto de São José), de 22 de novembro de 1969; Considerando que o Congresso Nacional aprovou, pelo Decreto Legislativo no 89, de 3 de dezembro de 1998, solicitação de reconhecimento da competência obrigatória da Corte Interamericana de Direitos Humanos, em todos os casos relativos à interpretação ou aplicação da Convenção, de acordo com o previsto no art. 62 daquele instrumento; Considerando que a Declaração de aceitação da competência obrigatória da Corte Interamericana de Direitos Humanos foi depositada junto à Secretaria-Geral da Organização dos Estados Americanos em 10 de dezembro de 1998, DECRETA: Art. 1o É reconhecida como obrigatória, de pleno direito e por prazo indeterminado, a competência da Corte Interamericana de Direitos Humanos em todos os casos relativos à interpretação ou aplicação da Convenção Americana de Direitos Humanos (Pacto de São José), de 22 de novembro de 1969, de acordo com art. 62 da citada Convenção, sob reserva de reciprocidade e para fatos posteriores a 10 de dezembro de 1998. Art. 2o Este Decreto entra em vigor na data de sua publicação. Brasília, 8 de novembro de 2002; $181^{\circ}$ da Independência e $114^{\circ}$ da República. (grifo nosso) 
realização de recomendações e relatórios (através de suas relatorias especiais) acerca das condições dos direitos humanos e sua efetivação em território nacional ${ }^{5}$.

Destarte, o SIDH não quedou inerte diante da realidade fática derivada da pandemia. $\mathrm{A}$ CIDH adotou a Resolução 01/2020, intitulada “Pandemia e Direitos Humanos nas Américas”, o documento visa orientar a atuação dos Estados americanos no enfrentamento da pandemia, sem que isso envolva a violação e a supressão massiva e sistemática de direitos humanos:

As Américas são a região mais desigual do planeta, caracterizada por profundas lacunas sociais nas quais a pobreza e a miséria são problemas transversais para todos os Estados da região; bem como a falta ou precariedade do acesso à água potável e ao saneamento básico; a insegurança alimentar, a degradação ambiental e a falta de moradia ou habitações adequadas. Além disso, as altas taxas de trabalho informal e vínculos precários afetam muitas pessoas na região, tornando ainda mais preocupante o impacto socioeconômico do COVID19. Tudo isso dificulta ou impede milhões de pessoas de tomar medidas básicas de prevenção contra a doença, especialmente nos que se refere aos grupos em situação de particular vulnerabilidade. (CIDH, 2020, p. 03 - tradução nossa).

Na mesma vereda, a Corte IDH exarou a Declaração 01/2020 sobre os problemas e desafios da pandemia e como eles devem ser abordados em uma perspectiva de respeito aos direitos humanos, às obrigações internacionais assumidas pelos Estados e aos parâmetros jurídicos ditados pela jurisprudência da Corte $\mathrm{IDH}^{7}$.

Ademais, a Presidenta da Corte Interamericana, no uso de suas atribuições regimentais, proferiu decisão concedendo medidas provisórias de urgência, no âmbito do caso Vélez Loor vs. Panamá, para que o referido país latinoamericano adotasse medidas imediatas para proteger os migrantes irregulares apreendidos pelas autoridades panamenhas e institucionalizados em um centro de detenção conhecido como "La Peñita”.

\footnotetext{
${ }^{5}$ Artigo 41 e seguintes do Pacto de San José.

${ }^{6}$ Resolução 01/2020 da Comissão Interamericana de Direitos Humanos. Pandemia e Direitos Humanos nas Américas. Disponível em: <https://www.oas.org/es/cidh/decisiones/pdf/Resolucion-1-20-es.pdf>

7 Declaração n. ${ }^{\circ}$ 01/2020 da Corte Interamericana de Direitos Humanos está disponível na íntegra em: < http://www.corteidh.or.cr/docs/comunicados/cp_27_2020.pdf>.
} 
Nesta importante decisão, a proteção dos direitos à liberdade, vida e saúde dos migrantes, resguardados pelo Pacto de San José, foi o fundamento da decisão que ordena ao Panamá a adoção de medidas de prevenção ao risco de contágio dos migrantes pelo COVID19, além de determinar que o Estado se abstenha detê-los por prazo indeterminado, uma vez que as medidas sanitárias restritivas não poderiam tornar válidas as prisões ilegais dos migrantes irregulares ${ }^{8}$.

Acerca dos refugiados, é despicienda a necessidade de realizar grandes ilações acerca das suas condições precárias de desfrute dos direitos humanos. Essas pessoas, no geral, deixam sua terra natal pois suas vidas correm perigo, uma vez que estão sujeitas às violações sistemáticas e generalizadas de seus direitos fundamentais.

No âmbito dos deslocamentos humanos nas américas, são os venezuelanos, haitianos, cubanos, chineses e bengaleses que representam a maior parte dos refugiados que buscam acolhimento no Brasil, segundo dados do Alto Comissariado da ONU para Refugiados?

Essas pessoas, como dito alhures, se encontram em situação de extrema vulnerabilidade. A preocupação do SIDH, neste contexto, é permitir que as nações continuem recebendo o fluxo de refugiados, sem olvidar dos standards mínimos de garantias e direitos que tais pessoas devem gozar, levadas em conta as questões sanitárias da pandemia.

Neste sentido, o governo brasileiro, nas esferas municipais, estaduais e federal estão adotando algumas medidas a fim de efetivar um mínimo de dignidade para essas pessoas durante a situação de excepcionalidade vivida neste momento. Ainda que a implementação de algumas dessas medidas dependa de intervenção do poder judiciário, na prática, os refugiados têm direito à renda emergencial (auxílio-emergencial - Lei 13.982/2020) estabelecida pelo

\footnotetext{
${ }^{8}$ CORTE INTERAMERICANA DE DERECHOS HUMANOS. Resolución de la Presidenta de la Corte Interamericana de Derechos Humanos de 26 de Mayo de 2020 Adopción de Medidas Urgentes Caso Vélez Loor Vs. Panamá. San josé, 26 de maio de 2020. Disponível em: <http://www.corteidh.or.cr/docs/medidas/velez_se_01.pdf>. Acesso em 24 de junho de 2020.

${ }^{9}$ Dados extraídos do sítio eletrônico da ACNUR. DIsponível em: $<\underline{\text { https://www.acnur.org/portugues/dados-sobre- }}$ refugio/>.
} 
Governo Federal, bem como acesso aos serviços de saúde e assistência social estaduais e municipais.

Não obstante, relativamente à regularização dos refugiados Brasil, o CONARE (órgão responsável pela análise dos pedidos de refúgio) suspendeu todos os prazos e atos processuais referentes ao reconhecimento da condição de refugiado, sem obstar o acesso dos requerentes aos serviços públicos básicos, ainda que sem o reconhecimento oficial da condição de refugiado e os documentos emitidos pelas autoridades brasileiras (Vide: ação civil pública n 5007915 28.2020.4.03.6100 de 04/05/2020).

Ademais, a validade dos documentos dos refugiados regularizados perante o Poder Público foi prorrogada, a fim de evitar transtornos a essas pessoas, como a necessidade de deixar o isolamento social em busca da renovação de seus registros civis e etc.

Em relação às políticas públicas locais, é de salutar importância aquela desenvolvida pelo Município de São Paulo/SP, cuja Secretaria Municipal de Direitos Humanos e Cidadania (SMDHC) divulgou um canal para coleta de denúncias sobre de a negativa de acesso de imigrantes a serviços e direitos essenciais ${ }^{10}$. Todas as iniciativas apontadas contemplam as enunciações das Resoluções exaradas pela Comissão Interamericana de Direitos Humanos e pela Corte IDH, ainda que dependam da atuação da Sociedade Civil Organizada, do Poder Judiciário, Ministério Público e Defensorias Públicas para a escorreita efetivação.

O cumprimento desses deveres enunciados pelo SIDH em relação aos refugiados, pelas autoridades brasileiras, demonstra que o funcionamento das instituições e dos sistemas de checks and balances ${ }^{11}$ garantem que o Estado brasileiro não seja responsabilizado no âmbito interamericano por violações sistemáticas e generalizadas dos direitos dos refugiados durante a pandemia. E, principalmente, garante um mínimo existencial digno para irmãos cuja humanidade foi negada, postos à margem de suas sociedades e forçados a deixar sua nação.

\footnotetext{
${ }^{10}$ Disponível em https://www.migramundo.com/ veja-como-imigrantes-em-sp-podem-denunciar-nega - cao-aoauxilio-emergencial-e-a-outros-direitos/amp/. Último acesso em 13.06.2020.

11 Disponível em <http://www.brazil.gov.br/about-brazil/news/2018/11/checks-and-balances-ensure-harmonybetween-powers>. Último acesso em 13.06.2020.
} 


\section{CONSIDERAÇÕES FINAIS}

Ao apresentar os dados e informações anteriores, o presente trabalho questiona quais são as ações realizadas em auxilia a comunidade de refugiados. O Governo brasileiro aprova diversos pedidos de refugiados (o que provavelmente diminuirá em 2020, haja vista o fechamento das fronteiras) - nesse cenário, a atuação do terceiro setor e de instituições internacionais como a ACNUR e o Sistema Interamericano de Direitos Humanos (SIDH) se mostra extremamente necessária, não apenas na destinação de recursos no auxilio ao combate ao COVID-19 dentro da comunidade de refugiados, como também na elaboração de planos de ação para aprimorar as respostas, em emergências sanitárias.

O fechamento das fronteiras, quando falamos em deslocamento de seres humanos, apresenta contornos mais complexos do que apenas uma simples questão administrativa dos Estados. Ao impedir seres humanos de adentrar um território, falamos também sobre hospitalidade. E, no caso de uma pandemia, as consequências podem ser graves a quem terá seu acesso negado no país de acolhimento. Para os refugiados, por sua vez, mais ainda, não ser acolhido não é uma opção: o cerne informativo da proteção ao refúgio é exatamente a impossibilidade de retorno ao lugar de origem, em razão do fundado temor de perseguição. A violação do Princípio do Non-Refoulement, que já poderia significar sua morte ou grave violação de direitos humanos em uma conjuntura dita normal, mais ainda, em uma emergência sanitária, tornar-se-á sombrio.

Conforme foi visto, é necessário conferir atenção e auxílio para a comunidade, corroborando para o que foi pactuado por diversos países na esfera internacional. Nesse sentido, também se analisou a forma como a Organização Mundial da Saúde tem, em parceria com o ACNUR, tentado elaborar respostas para a primeira Emergência de Saúde Pública de Importância Internacional do século XXI, após uma longa evolução histórica sobre questões de saúde, ao longo dos séculos, desde as Conferências Sanitárias Internacionais, no século XIX. A maneira como os Estados lidarão em caráter doméstico com a crise de saúde pública é um dos elementos determinantes, senão o mais importante, do combate a uma pandemia. 
E o Brasil, historicamente visto como um país acolhedor e simpático aos fluxos migratórios, apresenta uma face distinta, quando se toma por base os dados referentes à migração. A despeito de ter uma das legislações mais modernas sobre o tema, especialmente quanto à proteção de refugiados, os priva de autonomia e singularidade - algo especialmente grave para dois grupos, mulheres e crianças, em razão da maior vulnerabilidade e exposição a riscos.

Assim, a forma como o Sistema Interamericano de Direitos Humanos lida com o acolhimento a migrantes, a despeito de seu status migratório, mas com especial atenção a refugiados e deslocados forçados, confere ênfase adicional à necessidade de proteção, ainda que, mais uma vez, a efetividade e sucesso das medidas de combate e contenção de danos, em uma hipótese na qual respostas humanitárias e sanitárias rápidas são necessárias, dependerá a nível interno, de forma bem engendrada ou não, da capacidade reativa dos Estados. 


\section{REFERÊNCIAS}

ACNUR. Convenção Relativa ao Estatuto dos Refugiados. In IDEM. Manual de procedimentos e critérios a aplicar para determinar o estatuto de refugiado. Lisboa: ACNUR, 1996.

ARENDT, Hannah. We refugees, 1943. In: International Refugee Law. Routledge, 2017. p. 3-12.

BRASIL. Constituição (1988). Constituição da República Federativa do Brasil. Brasília, DF: Senado Federal: Centro Gráfico, 1988, 292 p.

BRASIL. (2019). Documento Refúgio em números 2019. Versão 23 (on-line). Disponível em <https://www.acnur.org/portugues/wp-content/uploads/2019/07/Refugio-em-

nu\%CC\%81meros_versa\%CC\%83o-23-de-julho-002.pdf >. Acesso em: 07 maio 2020;

BRASIL. Lei $n^{\circ}$ 9.474, de 22 de julho de 1997. Define mecanismos para a implementação do Estatuto dos Refugiados de 1951, e determina outras providências. Diário Oficial da União, Brasília, DF, 22 de jul. 1997. Disponível em: <http://www.planalto.gov.br/ccivil_03/leis/L9474.htm>. Acesso em: 26 abril 2020.

BRASIL. (2019). Refúgio em números traz dados sobre a realidade do refúgio no Brasil. Publicado em <https://www.justica.gov.br/news/collective-nitf-content-1564080197.57>. Acesso em: 07 maio 2020;

BRASIL. (2017). Refúgio em números 2010-2016. Ed. 2. V. 5.0. (on-line). Disponível em <https://www.justica.gov.br/seus-direitos/refugio/anexos/2deg-edicao-refugio-em-numeros2010-2016-v-5-0-final.pdf.>. Acesso em: 07 maio 2020;

CAULFORD, Paul; VALI, Yasmin. Providing health care to medically uninsured immigrants and refugees. Cmaj, v. 174, n. 9, p. 1253-1254, 2006

CORTE INTERAMERICANA DE DERECHOS HUMANOS. Resolución de la Presidenta de la Corte Interamericana de Derechos Humanos de 26 de Mayo de 2020 Adopción de Medidas Urgentes Caso Vélez Loor Vs. Panamá. San josé, 26 de maio de 2020. Disponível em: <http://www.corteidh.or.cr/docs/medidas/velez_se_01.pdf>. Acesso em 24 de junho de 2020.

HUBER, Valeska. The unification of the globe by disease? The international sanitary conferences on cholera, 1851-1894. The Historical Journal, v. 49, n. 2, p. 453-476, 2006.

JUBILUT, Luciana. 0 Direito Internacional dos Refugiados e sua Aplicação no Ordenamento Jurídico Brasileiro. São Paulo: Método, 2007.

KLUGE, Hans Henri P. et al. Refugee and migrant health in the COVID-19 response. The Lancet, v. 395, n. 10232, p. 1237-1239, 2020.

MAZZUOLI, Valério de Oliveira. Curso de Direito Internacional Público. São Paulo: Revista dos Tribunais, 2007.

MEZZADRA, Sandro. Multidão e Migrações: a autonomia dos migrantes. Revista ECO-Pós, v. 15, n. 2, p. 70-107, 2012. 
ONU. (2018). Brasil receber mais de 61 mil pedidos de refúgio de venezuelanos em 2018. Publicado em <https://nacoesunidas.org/brasil-recebeu-mais-de-61-mil-pedidos-de-refugiode-venezuelanos-em-2018/>. Acesso em: 10 maio 2020;

ONU. (1951). Convenção Relativa ao Estatuto do Refugiado. Publicado em <https://www.acnur.org/fileadmin/Documentos/portugues/BDL/Convencao_relativa_ao_Estatu to_dos_Refugiados.pdf >. Acesso em: 28 abril 2020;

PEREIRA, Giselda Fernanda. $\mathbf{O}$ português como língua de acolhimento e interação: a busca pela autonomia por pessoas em situação de refúgio no Brasil. Cadernos de Pós-Graduação em Letras. São Paulo, vol. 17, n. 1, p. 118-134. ISSN 1809-4163. Jan/Jun 2017 (on-line).

RAJU, Emmanuel; AYEB-KARLSSON, Sonja. COVID-19: How do you self-isolate in a refugee camp?. International Journal of Public Health, p. 1, 2020.

RODRIGUES; Jana Braz; BIAZATTI, Bruno de Oliveira. Soberania e Direitos Humanos no âmbito do direito internacional contemporâneo. In: Anuário Brasileiro de Direito = Brazilian Yearbook of International Law = Annuaire Brésilien de Droit International / Coordenador: Leonardo Nemer Caldeira Brant - v.1, n. 20, 2016 - Belo Horizonte: CEDIN, 2016.

SAN LAU, Ling et al. COVID-19 in humanitarian settings and lessons learned from past epidemics. Nature Medicine, v. 26, n. 5, p. 647-648, 2020.

SANTOS, M. Por uma outra globalização. Rio de janeiro: Record. 2011.

SPIVAK, Gayatri Chakravorty. Pode o subalterno falar? Belo Horizonte: Ed. UFMG, 2014.

TAVARES, André Ramos. Curso de direito constitucional. São Paulo: Saraiva, 2002.

UNHCR. Coronavirus Emergency Appeal: UNHCR's Preparedness and Response Plan (revised) 30 de março de 2020. Disponível em: <https://reporting.unhcr.org/covid-19-appeal> Acesso: em 07 jul. 2020.

WORLD HEALTH ORGANIZATION. Constitution of the World Health Organization, 1948. Disponível em: <https://apps.who.int/gb/bd/PDF/bd47/EN/constitution-en.pdf?ua=1> Acesso em: 07 jul. 2020. 


\title{
APÊNDICE 1 - DECLARAÇÃO 01/2020 DE 09 ABRIL DE 2020 DA CORTE INTERAMERICANA DE DIREITOS HUMANOS ${ }^{12}$
}

\begin{abstract}
COVID-19 E DIREITOS HUMANOS: OS PROBLEMAS E DESAFIOS DEVEM SER ABORDADOS A PARTIR DE UMA PERSPECTIVA DE DIREITOS HUMANOS E COM RESPEITO ÀS OBRIGAÇ̃̃ES INTERNACIONAIS
\end{abstract}

San José, Costa Rica, 14 de abril de 2020.- A Corte Interamericana de Direitos Humanos adotou, na última quinta-feira 9 de abril de 2020, uma Declaração intitulada "COVID-19 e Direitos Humanos: Os problemas e desafios devem ser abordados a partir de uma perspectiva de Direitos Humanos e com respeito às obrigações internacionais”.

A Presidente da Corte Interamericana, Juíza Elizabeth Odio Benito indicou que esta Declaração tem por objeto que "os Estados tenham presente e não esqueçam suas obrigações internacionais e a jurisprudência da Corte para assegurar a efetiva vigência e proteção dos direitos humanos na resposta e contenção à pandemia".

\section{DECLARAÇ̃̃O DA CORTE INTERAMERICANA DE DIREITOS HUMANOS 1/20 9 DE ABRIL DE 2020}

COVID-19 E DIREITOS HUMANOS: OS PROBLEMAS E DESAFIOS DEVEM SER ABORDADOS A PARTIR DE UMA PERSPECTIVA DE DIREITOS HUMANOS E COM RESPEITO ÀS OBRIGAÇÕES INTERNACIONAIS

A Corte Interamericana de Direitos Humanos, como órgão de proteção dos direitos humanos, consciente dos problemas e desafios extraordinários que os Estados americanos, a sociedade como um todo, cada família e cada indivíduo estão enfrentando como resultado da pandemia global causada pelo coronavírus COVID-19, emite a presente declaração para exortar à adoção e implementação de medidas, dentro da estratégia e dos esforços que os Estados Membros da Convenção Americana sobre Direitos Humanos estão realizando para enfrentar e conter esta situação, que diz respeito à vida e à saúde pública. As medidas devem ser tomadas no âmbito do Estado de Direito, em plena observância aos instrumentos interamericanos de

\footnotetext{
${ }^{12}$ Acesse a declaração completa em: http://www.corteidh.or.cr/docs/comunicados/cp_27_2020_port.pdf
} 
proteção dos direitos humanos e à jurisprudência deste Tribunal. Em particular, considera-se que:

- Os problemas e desafios extraordinários causados pela atual pandemia devem ser enfrentados por meio do diálogo e da cooperação internacional e regional conjunta, solidária e transparente entre todos os Estados. O multilateralismo é essencial para coordenar os esforços regionais para conter a pandemia.

- Os organismos multilaterais, qualquer que seja sua natureza, devem ajudar e cooperar conjuntamente com os Estados, sob uma abordagem de direitos humanos, na busca de soluções para os problemas e desafios presentes e futuros que a atual pandemia está causando e causará.

- Todas as medidas adotadas pelos Estados para enfrentar esta pandemia que possam afetar ou restringir o gozo e o exercício de direitos humanos devem ser limitadas no tempo, legais, condizentes com os objetivos definidos conforme critérios científicos, razoáveis, estritamente necessárias e proporcionais e consistentes com os demais requisitos desenvolvidos na legislação interamericana de direitos humanos.

- Deve-se ter cuidado para que o uso da força para implementar as medidas de contenção por parte dos funcionários encarregados do cumprimento da lei esteja em conformidade com os princípios de necessidade absoluta, proporcionalidade e precaução, de acordo com a jurisprudência da Corte Interamericana.

- Dada a natureza da pandemia, os direitos econômicos, sociais, culturais e ambientais devem ser garantidos sem discriminação a todas as pessoas sob a jurisdição do Estado e, em particular, àqueles grupos que são desproporcionalmente afetados por estarem em situação de maior vulnerabilidade, como idosos, crianças, pessoas com deficiência, migrantes, refugiados, apátridas, pessoas privadas de liberdade, LGBTI, mulheres grávidas ou em período pós-parto, comunidades indígenas, afrodescendentes, pessoas que vivem do trabalho informal, população de favelas e bairros de moradia precária, pessoas em situação de rua, pessoas em situação de 
pobreza e profissionais da área de saúde que lidam com esta emergência.

- $\quad$ Nestes momentos, adquire ênfase especial a garantia, de forma oportuna e apropriada, dos direitos à vida e à saúde de todas as pessoas sob a jurisdição do Estado, sem qualquer discriminação, incluindo aos idosos, migrantes, refugiados e apátridas, e membros de comunidades indígenas.

- $\quad$ O direito à saúde deve ser garantido respeitando-se a dignidade humana e observandose os princípios fundamentais da bioética, em conformidade com os padrões interamericanos quanto à sua disponibilidade, acessibilidade, aceitabilidade e qualidade, adequados às circunstâncias geradas por esta pandemia. Portanto, os trabalhadores e as trabalhadoras da área de saúde devem receber os suprimentos, equipamentos, materiais e instrumentos que protejam sua integridade, vida, saúde, e que thes permitam desempenhar seu trabalho em termos razoáveis de segurança e qualidade.

- $\quad$ Tendo em vista as medidas de isolamento social que podem levar a um aumento exponencial da violência contra mulheres e meninas em suas casas, é necessário enfatizar o dever do Estado de devida diligência estrita com respeito ao direito das mulheres a viverem uma vida livre de violência e, portanto, todas as ações necessárias devem ser tomadas para prevenir casos de violência de gênero e sexual; ter mecanismos seguros de denúncia direta e imediata; e reforçar a atenção às vítimas.

- Dado o alto impacto que a COVID-19 pode ter com relação às pessoas privadas de liberdade em prisões e outros centros de detenção e, tendo em vista a posição especial de garantidor do Estado, é necessário reduzir os níveis de superlotação e superpopulação para, dessa forma, promover de forma racional e ordenada alternativas à privação de liberdade.

- $\quad$ Deve-se ter o cuidado para que se preservem os postos de trabalho e se respeitem os direitos trabalhistas de todos os trabalhadores e trabalhadoras. Também devem ser adotadas e promovidas medidas para mitigar o possível impacto sobre as fontes de trabalho e renda de 
todos os trabalhadores e trabalhadoras, assegurando-se a renda necessária à subsistência em condições de dignidade humana. Em razão das medidas de isolamento social e do impacto que isso gera na economia pessoal e familiar, deve-se buscar mecanismos para fornecer alimentos e remédios básicos, bem como, suprir outras necessidades elementares para aqueles que não possam realizar suas atividades normais, e também para a população em situação de rua.

- $\quad 0$ acesso à informação verdadeira e confiável, assim como à Internet, é essencial. Medidas adequadas devem ser tomadas para garantir que o uso da tecnologia de vigilância, para monitorar e rastrear a disseminação do coronavírus COVID-19, seja limitado e proporcional às necessidades de saúde, e não envolva uma interferência desmedida e lesiva à privacidade, à proteção de dados pessoais e à observância ao princípio geral de não-discriminação.

- É indispensável que se garanta o acesso à justiça e aos mecanismos de denúncia, bem como que se proteja, particularmente, a atividade das/dos jornalistas, e das defensoras e defensores de direitos humanos, a fim de monitorar todas as medidas adotadas que afetam ou restringem os direitos humanos, com o objetivo de avaliar sua conformidade com instrumentos e normas interamericanas, assim como, suas consequências para os indivíduos.

- É pertinente alertar aos órgãos ou agências responsáveis pelo combate à xenofobia, racismo e qualquer outra forma de discriminação, para que tomem extremo cuidado no sentido de garantir que, durante a pandemia, ninguém promova surtos dessa natureza por meio de denúncias falsas ou incitação à violência. 


\section{APÊNDICE 2 - RESOLUÇÃO N 1/2020 \\ PANDEMIA E DIREITOS HUMANOS NAS AMÉRICAS}

(Aprovada pela CIDH em 10 de abril de 2020)

\section{A. INTRODUÇÃO}

As Américas e o mundo enfrentam atualmente uma emergência sanitária global sem precedentes provocada pela pandemia do vírus que causa a COVID-19, ante a qual as medidas adotadas pelos Estados na atenção e contenção do vírus devem ter como centro o pleno respeito aos direitos humanos.

A pandemia da COVID-19 pode afetar gravemente a plena vigência dos direitos humanos da população em virtude dos sérios riscos que a doença representa para a vida, a saúde e a integridade pessoal, bem como seus impactos de imediato, médio e longo prazo sobre as sociedades em geral e sobre as pessoas e grupos em situação de especial vulnerabilidade.

As Américas são a região mais desigual do planeta, caracterizada por profundas disparidades sociais em que a pobreza e a pobreza extrema constituem um problema transversal a todos os Estados da região, bem como pela falta ou precariedade no acesso a água potável e saneamento, insegurança alimentar, situações de contaminação ambiental e falta de moradia ou de hábitat adequado. A isso somam-se altas taxas de informalidade do trabalho e renda precária que afetam grande número de pessoas na região e tornam ainda mais preocupante o impacto socioeconômico da COVID-19. Tudo isto dificulta ou impede que milhões de pessoas tomem medidas básicas de prevenção contra a doença, em particular quando afeta grupos em situação de especial vulnerabilidade.

A região é caracterizada por altos índices de violência generalizada, especialmente a violência por razões de gênero, raça ou etnia, bem como pela persistência de flagelos tais como a corrupção e a impunidade. Além disso, na região prevalece por parte dos cidadãos e cidadãs o exercício do direito ao protesto social, num contexto de repressão mediante o uso desproporcional da força, bem como de atos de violência e vandalismo, graves crises penitenciárias que afetam a grande maioria dos países e a profundamente preocupante extensão do fenômeno das migrações, do deslocamento forçado interno, de pessoas refugiadas 
e apátridas, além da discriminação estrutural contra grupos em situação de especial vulnerabilidade.

Neste contexto, a pandemia representa desafios ainda maiores para os Estados das Américas, tanto em termos de políticas e medidas sanitárias, como em capacidade econômica, que permitam adotar medidas de atenção e contenção urgentes e necessárias para proteger efetivamente suas populações, de acordo com o Direito Internacional dos Direitos Humanos. Por sua vez, a pandemia gera impactos diferenciados e intersecionais sobre a realização dos direitos econômicos, sociais, culturais e ambientais (DESCA) para certos coletivos e populações em situação de especial vulnerabilidade, motivo pelo qual se torna essencial a adoção de políticas para prevenir eficazmente o contágio, bem como de medidas de segurança social e acesso a sistemas de saúde pública que facilitem o diagnóstico e tratamento oportuno e com custo módico, a fim de proporcionar às populações em situação de vulnerabilidade uma atenção integral à saúde física e mental, sem discriminação.

Além disso, os sistemas de saúde dos Estados da região estão ou podem ficar ainda mais congestionados frente à magnitude da pandemia da COVID-19, em particular os que vivem na pobreza ou que não têm cobertura médica, caso necessitem de atenção médica ou hospitalização.

Até agora não se tem conhecimento de intervenções farmacêuticas viáveis para lutar contra a COVID19 e muitos países introduziram medidas de contenção que incluem quarentena, distanciamento ou isolamento social, fechamento de escolas e lojas, limitação de circulação em nível nacional e internacional, bem como orientações preventivas de higiene pessoal e comunitária.

Quanto às medidas de contenção para enfrentar e prevenir os efeitos da pandemia, a $\mathrm{CIDH}$ observa que foram suspensos e restringidos alguns direitos, e em outros casos foi declarado "estado de emergência”, "estado de exceção”, “estado de catástrofe por calamidade pública” ou "emergência sanitária”, através de decretos presidenciais e normas de diversa natureza jurídica com o fim de proteger a saúde pública e evitar o aumento do contágio. Além disso, foram estabelecidas medidas de diversos tipos que restringem os direitos de liberdade de expressão, o direito de acesso à informação pública, a liberdade pessoal, a inviolabilidade 
do domicílio e o direito à propriedade privada e recorreu-se ao uso de tecnologia de vigilância para rastrear a propagação do coronavírus e ao armazenamento de dados de forma maciça.

A Comissão Interamericana de Direitos Humanos (CIDH), com o apoio de suas Relatorias Especiais sobre os Direitos Econômicos, Sociais, Culturais e Ambientais e sobre Liberdade de Expressão, no exercício de seu mandato, aprova a presente resolução que estabelece padrões e recomendações, com a convicção de que as medidas adotadas pelos Estados na atenção e contenção da pandemia devem ter como centro o pleno respeito aos direitos humanos.

ACESSE A RESOLUÇÃO COMPLETA EM:

https://www.oas.org/pt/cidh/decisiones/pdf/Resolucao-1-20-pt.pdf 


\title{
APÊNDICE 3 - RESOLUCIÓN DE LA PRESIDENTA DE LA CORTE INTERAMERICANA DE DERECHOS HUMANOS DE 26 DE MAYO DE 2020
}

\author{
RESOLUCIÓN DE LA PRESIDENTA DE LA \\ CORTE INTERAMERICANA DE DERECHOS HUMANOS \\ DE 26 DE MAYO DE 2020 ADOPCIÓN DE MEDIDAS URGENTES
}

CASO VÉLEZ LOOR VS. PANAMÁ

El caso se refiere a la responsabilidad internacional del Estado por la detención migratoria de Jesús Vélez Loor, por las malas condiciones en el centro de detención y por la falta de un debido proceso.

ACESSE A RESOLUÇÃO COMPLETA EM:

https://www.corteidh.or.cr/cf/Jurisprudencia2/ficha_tecnica.cfm?nld_Ficha=341\&lang=es 


\section{(ㄷ) (1)}

